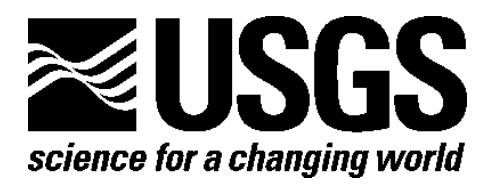

Eastern Geographic Science Center

\title{
Shenandoah National Park Phenology Project-Weather Data Collection, Description, and Processing
}

By John W. Jones, Danielle P. Aiello, and Jesse D. Osborne

Open-File Report 2010-1272 


\section{U.S. Department of the Interior \\ KEN SALAZAR, Secretary}

\section{U.S. Geological Survey \\ Marcia K. McNutt, Director}

U.S. Geological Survey, Reston, Virginia 2010

For product and ordering information:

World Wide Web: http://www.usgs.gov/pubprod

Telephone: 1-888-ASK-USGS

For more information on the USGS-the Federal source for science about the Earth,

its natural and living resources, natural hazards, and the environment:

World Wide Web: http://www.usgs.gov

Telephone: 1-888-ASK-USGS

Suggested citation:

Jones, J. W., Aiello, D. P., Osborne, J. D., 2010, Shenandoah National Park Phenology Project-Weather data collection, description, and processing: U.S. Geological Survey Open-File Report 2010-1272, 17 p.

Any use of trade, product, or firm names is for descriptive purposes only and does not imply endorsement by the U.S. Government.

Although this report is in the public domain, permission must be secured from the individual copyright owners to reproduce any copyrighted material contained within this report. 


\section{Contents}

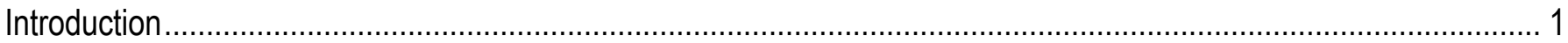

Methods

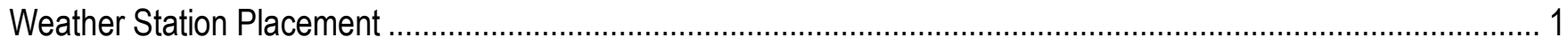

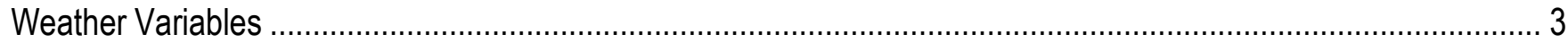

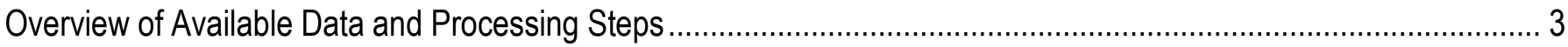

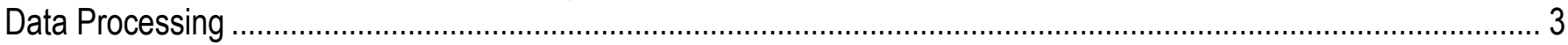

Time Series Inconsistencies in the Weather Station Data .............................................................................. 8

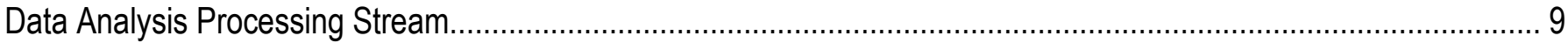

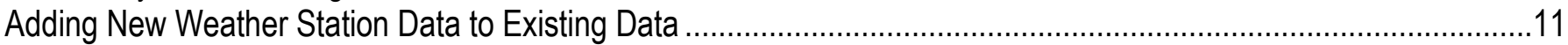

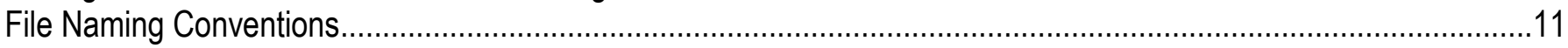

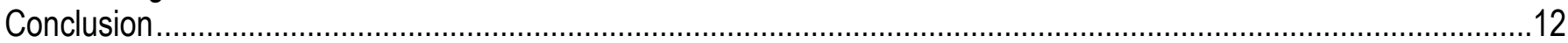

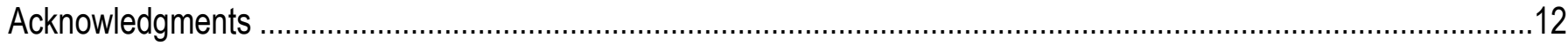

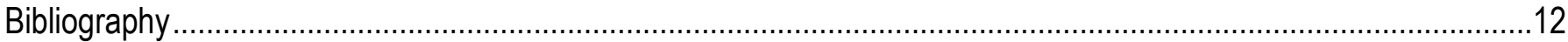

Appendix 1. Detailed flowchart of data processing steps..............................................................................13

Appendix 2. Macros used in processing data for the Shenandoah National Park Phenology Project...........................14

\section{Figures}

1. Map of Shenandoah National Park depicting locations of weather stations ........................................... 2

2. Simple schematic of weather station Data Cleaning and Data Analysis steps........................................ 3

3. Chart depicting temporal extent of existing air temperature data per weather station between January 2005 and July 2009, Shenandoah National Park.

4. Average monthly maximum air temperature $\left({ }^{\circ} \mathrm{C}\right)$ from the Madison River station, Shenandoah National Park.

5. Example showing how to assess what values should be given to the 'max_columna' and 'min_columna' code within the grabber and mo_grabber macros

\section{Tables}

1. Headers for weather data DAT files.

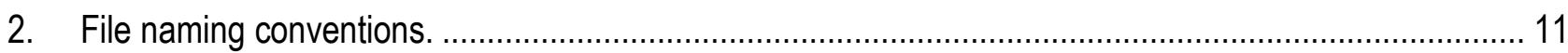




\title{
Shenandoah National Park Phenology Project-Weather Data Collection, Description, and Processing
}

\author{
By John W. Jones, Danielle P. Aiello, and Jesse D. Osborne
}

\section{Introduction}

The weather data described in this document are being collected as part of a U.S. Geological Survey (USGS) study of changes in Shenandoah National Park (SNP) landscape phenology (Jones and Osbourne, 2008). Phenology is the study of the timing of biological events, such as annual plant flowering and seasonal bird migration. These events are partially driven by changes in temperature and precipitation; therefore, phenology studies how these events may reflect changes in climate. Landscape phenology is the study of changes in biological events over broad areas and assemblages of vegetation. To study climate-change relations over broad areas (at landscape scale), the timing and amount of annual tree leaf emergence, maximum foliage, and leaf fall for forested areas are of interest.

Changes in land use or disturbances such as defoliation by insects, disease, or fire all affect the composition and amount of tree canopy in a forest. Observing and understanding the complex ways that global or regional-scale climate change combines with these disturbances to affect forest growth patterns and succession is difficult, especially for regions where changes in climate are not the most extreme, such as the mid-latitude forests of the Eastern United States.

The forests of the SNP in the Blue Ridge province of Virginia have been protected from major land-use change for many decades. In addition, the National Park Service (NPS) has recorded the dates and often the location of disturbances such as fires and insect infestations. These factors make the SNP an excellent "laboratory" in which to conduct an experiment.

To better link vegetation changes with climate, weather data are necessary. This report documents weather-station data collection and processing procedures used in the Shenandoah National Park Phenology Project. For more information about the SNP phenological study, read USGS Fact Sheet 2008-3046, Detecting Evidence of Climate Change in the Forests of the Eastern United States, which is free and available for download at http://pubs.usgs.gov/fs/2008/3046.

\section{Methods}

\section{Weather Station Placement}

In consultation with NPS authorities, meteorological stations were placed in the SNP at locations selected after considering forest-cover type, the slope of the ground, the direction in which the ground is facing (aspect), and whether there is adequate distance from a trail or historic feature (fig. 1). Six of the stations were installed during spring of 2005. An additional station (Meadow Spring) was added in 2008. Additional stations may be added as resources allow. Five of these stations must be visited periodically to download data. However, the Meadow Spring and Pocosin stations provide continuous 
data retrieval through automated communications with weather satellites. Their data are available in real time via the internet at http://egsc.usgs.gov/shenandoah.html.

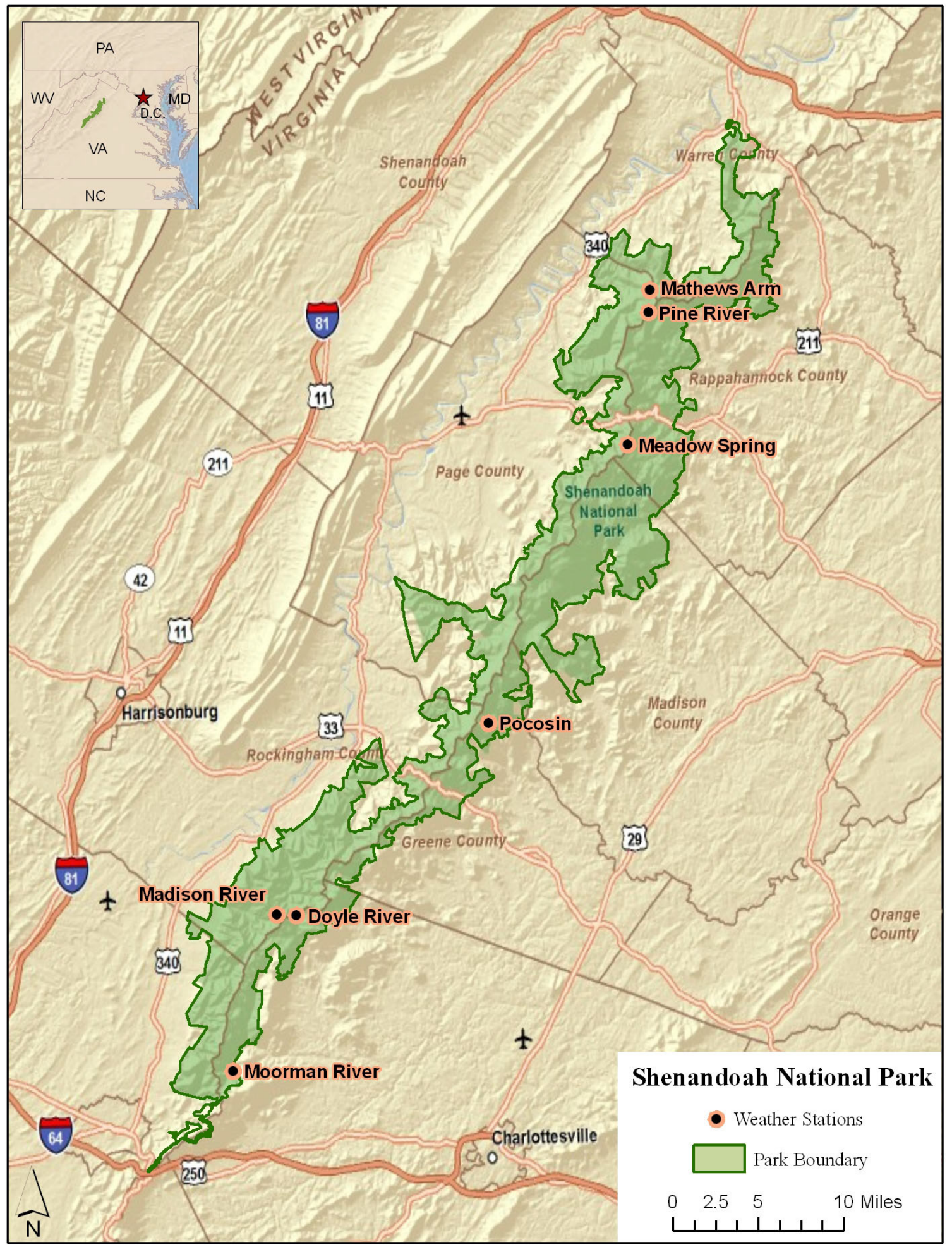

Figure 1. Map of Shenandoah National Park depicting locations of weather stations. Sources: Environmental Science Research Institute, National Park Service, U.S. Geological Survey. 


\section{Weather Variables}

The instruments on each of the weather stations measure three variables: air temperature, soil temperature, and relative humidity (RH). At two of the sites (Meadow Spring and Pocosin) wind speed, wind direction, solar radiation, and rainfall are also collected. All observations are recorded on an hourly basis.

\section{Overview of Available Data and Processing Steps}

The raw data are downloaded using Campbell Scientific ${ }^{\circledR}$ PC400 Datalogger Support Software ${ }^{\circledR}$ from the weather station data loggers to ASCII file format. These data must be reformatted and "cleaned" before they can be analyzed. Distribution files are in .dat file format. During the Data Cleaning Process and the Data Analysis steps, four workbooks (.xls files) are created for each weather station (fig. 2). First, a workbook is created for the Data Cleaning Process, as described in the next section. This workbook must have worksheets for raw and reorganized soil temperature, air temperature, and relative humidity data. The other three workbooks are created after the Data Cleaning Process is completed. There is one workbook for each data type: Soil, Air, and RH. In these workbooks the cleaned weather station data undergo basic analysis, and summary tables are created. The Data Cleaning Process and Data Analysis steps are simplistically represented in figure 2. A detailed flowchart of the data processing steps described within this document can be found in appendix 1 .

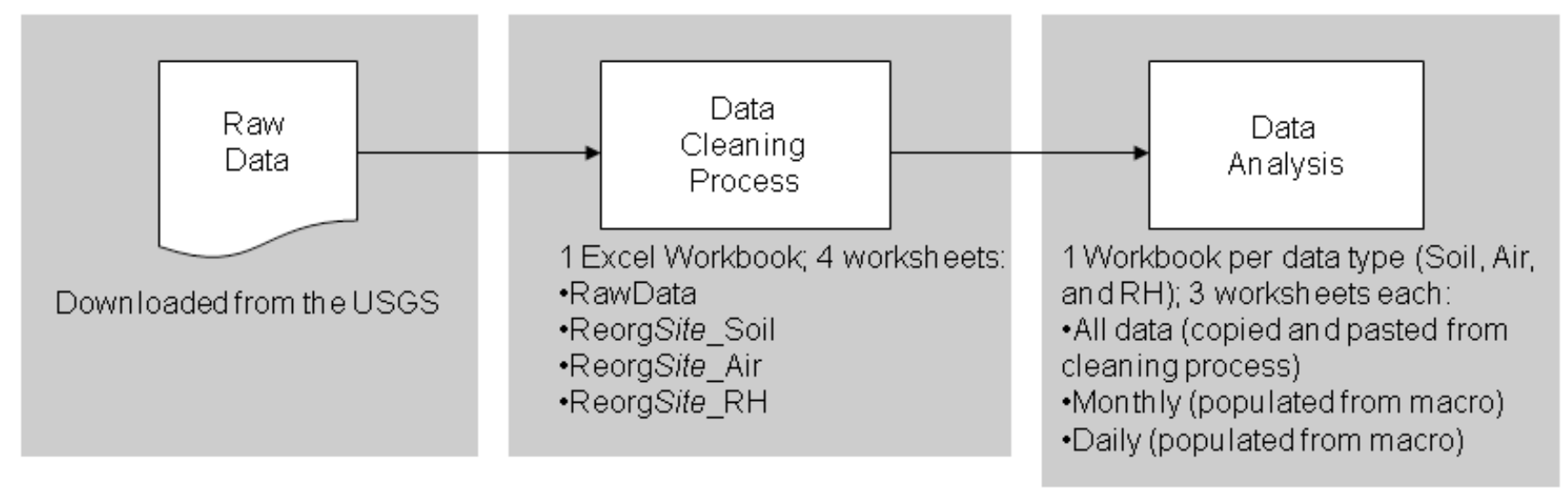

Figure 2. Simple schematic of weather station Data Cleaning and Data Analysis steps.

\section{Data Processing}

Data obtained directly from the five non-automated weather stations in SNP are preprocessed through a provisional Microsoft ${ }^{\circledR}$ Excel ${ }^{\circledR}$ workbook to filter out weather data that may be corrupt or invalid. The Data Cleaning Process takes place in a user-operated database along with a set of instructions to discriminate valid data from invalid data. It is important to note that the process involves some decisionmaking for identifying corrupt and invalid data collected by the weather stations, and user-intervention at this stage affects all data output.

The Data Cleaning Process begins with importing the data. The user performs the following operations. Please Note: The following directives were produced using Excel 2003, while Excel 2007 
commands are given within certain steps where necessary. Some options may be different in other versions of the Excel software.

1. Create a single worksheet named RawData in an Excel workbook named Cleanup_StationName.xls.

The headers (column names) for the .dat files are shown below (table 1) and can be pasted in the Excel spreadsheet using the Transpose option in the Paste Special dialog box. First, copy and paste the appropriate header list into a randomly chosen cell in the worksheet other than cell A1. Select the pasted list again to re-copy and Paste Special into cell A1 using the Transpose option. The text will now be horizontal to create the headers for each column. Please note that all temperature data are collected in degrees Celsius and that there are more data columns for the Pocosin and Meadow Spring stations than for the other five stations. This is due to the collection of soil temperature data at two depths and rain gages located at these two stations.

Table 1. Headers for weather data DAT files.

[temp=temperature; avg=average; $\max =$ maximum; $\min =$ minimum; $\mathrm{RH}=$ relative humidity; slrkW=solar radiation kilowatts; slrMJ=solar radiation megajoules; tot=total; $\mathrm{ws}=$ wind speed; winddir=wind direction; $\mathrm{ms}=$ meters per second; $\mathrm{N} / \mathrm{A}=\mathrm{not}$ applicable]

\begin{tabular}{lll}
\hline TableCellHeading & $\begin{array}{c}\text { Moorman River, Doyle } \\
\text { River, Mathews Arm, } \\
\text { Madison River, and } \\
\text { Pine River }\end{array}$ & $\begin{array}{c}\text { Pocosin and Meadow } \\
\text { Spring }\end{array}$ \\
\hline 1 & Input_type & Input_type \\
2 & Year & Year \\
3 & Day & Day \\
4 & Hour & Hour \\
5 & Soil_temp_avg & Air_temp_max \\
6 & Soil_Temp_max & Air_temp_min \\
7 & SoilMax_time & RH_max \\
8 & Soil_temp_Min & RH_min \\
9 & SoilMin_time & SlrkW_Max \\
10 & Air_temp_max & SlrMJ_TOT \\
11 & AirMax_time & SlrkW_2_Max \\
12 & Air_temp_min & SlrMJ_2_TOT \\
13 & AirMin_time & WS_ms_Max \\
14 & RH_max & WS_ms_Min \\
15 & RHMax_time & WindDir \\
16 & RH_min & Soil_Temp_Max \\
17 & RHMin_time & Soil_Temp_Min \\
18 & N/A & Soil_Temp_2_Max \\
19 & N/A & Soil_Temp_2_Min \\
20 & N/A & N/A \\
\hline & &
\end{tabular}


2. In Excel 2003 or earlier, use the import external data function under the Data pull-down menu on the toolbar, go to 'Import External Data', then 'Import Data'. In Excel 2007, select 'From Text' on the Data tab.

3. Locate the first .dat file (make sure the "Files of type' reads "All Files", not "All Data Sources", or else you will not be able to see your files at their location on the disk.

4. On the 'Text Import Wizard' prompt, make sure that the 'Delimited' radio button is selected and press 'Next'.

5. Under the 'Delimeters' box selection, unselect 'Tab' and then select 'Comma'. Press the 'Finish' button.

6. When asked, select the cell location that you would like the data to begin. For the first dataset of a series, this would logically be cell A2. The rest of these instructions will assume that you have pasted your first dataset into cell A2. Each successive dataset would logically be the next available cell after all existing datasets. You may find that there are more data columns than headers; these data will be removed in the cleaning process. Keep in mind that you do not have to import your data in any particular order, but see the note at the end of this sub-section before proceeding.

7. Press ' $O K$ '.

8. Repeat steps 3-8 for each successive .dat file dataset until all .dat files are entered into the worksheet.

Please note: We change the cell colors for each imported dataset as a simple way of visually tracking the origin of the datasets as they move through the procedure. This helps show which records overlap and the origin of errors. However, once the following step (duplicate record deletion) is completed, the origin of data can no longer be tracked this way.

\section{Identify Duplicate Records}

1. Select all of your data using the hot-key $\mathrm{Ctrl}+\mathrm{a}$ (be sure to select all your data every time you 'sort' the data).

2. If using Excel 2007, go to the Home tab on the toolbar, select Format, then 'Autofit Column Width'. In Excel 2003, under the Format pull-down menu on the toolbar, select 'Column', then 'AutoFit Selection'.

3. Under the Data pull-down menu (or Data tab in Excel 2007) on the toolbar, go to 'Sort'.

4. On the 'Sort' window prompt, under 'My data range has' select the 'Header row' option.

5. Then, using the drop-down boxes, Sort by "Year", then by "Day", then by "Hour" leaving the 'Ascending' radio button to its default position ('Smallest to Largest' in Excel 2007).

\section{Delete Duplicate Records}

1. Select all records $(\mathrm{Ctrl}+\mathrm{a})$.

2. If using Excel 2007, under the Data tab on the toolbar, go to the 'Data Tools' section and select 'Remove Duplicates'. Select 'My data has headers' and make sure that all possible columns are checked. If using Excel 2003, under the Data pull-down menu on the toolbar, go to 'Filter' then 'Advanced Filter'. Complete the following steps when using Excel 2003 to complete the process of deleting duplicate records. 
3. Click the radio button 'Filter the list, in-place'.

4. Under 'List Range', make sure that all your data are highlighted.

5. Check the box that reads, 'Unique records only', then click OK.

6. Depending on the size of your file, this may take a few minutes to process. Once it is finished, the filtered list will be displayed and the duplicate rows will be hidden. (Keep in mind that those hidden records still exist underneath the filtered display!) In Excel 2007, the duplicate records will have been removed completely after the process has run.

7. Under the Edit pull-down menu on the toolbar, go to 'Office Clipboard'. Make sure that the filtered list is still selected, and click 'copy' under the Edit pull-down menu.

8. Under the Data pull-down menu, click 'Filter' then 'Show All'.

9. Press the Delete key.

10. In the Clipboard on the right of your screen, click on the filtered list item to paste.

Please note: Once this step is complete, imported data can no longer be updated as an external dataset that is linked to the file. Also, the cell colors of the original datasets will be lost. It is best to reset the colors of all cells to 'No fill' at this point.

From this point on, only one variable is to be cleaned at a time. The raw data will stay as is, and the next steps will take place only on a certain data type in a single worksheet for that data type. Each time a data type is cleaned, the RawData worksheet must be copied and renamed, as described in Step 2 below.

1. Right-click the mouse on the RawData worksheet tab, then choose 'Move or Copy'.

2. Select the worksheet RawData and check the 'Create a copy' checkbox. Then, rename the new worksheet as "Reorg[sitename]_[variable type]" (for example, ReorgMormanR_Air). For the remainder of the procedure you will be working out of the new worksheet (not the RawData worksheet). After all data types have been cleaned with the steps that follow, there will be four worksheets in the Excel workbook: (1) RawData, (2) Reorg[sitename]_Air,

(3) Reorg[sitename]_Soil, and (4) Reorg[sitename]_RH.

The following steps are used to delete obviously inaccurate readings within the data.

1. Select all data.

2. Begin with cleaning the soil temperature data. Sort data as ascending by 'Soil_temp_avg', then by 'None', then by 'None'. (Note: there is no average soil temperature column for the Pocosin or Meadow Spring stations. The Soil_Temp_Max and Soil_Temp_Min columns will be evaluated for those two stations' soil temperature data.)

3. Examine the data. Any values for Soil Temperature that are $\leq-5^{\circ}$ or $\geq 33^{\circ} \mathrm{C}$ should raise a red flag. [Note: Readings for Air Temperature that are $\leq-25^{\circ}$ or $\geq 41^{\circ} \mathrm{C}$ should also be looked at more closely, and Relative Humidity readings should be between 0 and 100 percent.] It should be rather evident that inaccurate readings have been recorded if (1) a long list of the same value appears consistently throughout a certain period of time, (2) the list contains high negative values, (3) values occurring within a time period of just a few hours are inconsistent within a small sequence, (4) values are inconsistent with their respective Julian date or season, (5) records contain values of 6999 and 2599 in the $\min / \max$ fields (delete these), and (6) minimum values are greater than maximum values for the same records. 
4. Select all of the data and sort the data as descending by the same field. After the data have been flipped, repeat step 3.

5. Select all of the data and sort the data as ascending by Soil_Temp_Max. Repeat step 3 and 4.

6. Select all of the data and sort the data as ascending by Soil_Temp_Min. Repeat step 3 and 4.

7. When cleaning the Air Temperature and Relative Humidity data, both the 'min' and 'max' fields need to be examined with the above steps for these variables within their separate worksheets.

After all obviously inaccurate readings have been removed, sort the records in ascending order by 'Year', then 'Day', then 'Hour'. Create a date field in the format of $\mathrm{mm} / \mathrm{dd} / \mathrm{yyyy}$ from the Julian date serial number imbedded in the raw data with the following steps:

1. Select the field titled 'Soil_temp_avg' (or Air_temp_max for the Pocosin and Meadow Spring stations). Under the Insert pull-down menu on the toolbar, go to 'Columns'.

2. Repeat step 1 four times so that you now have four new empty column fields.

3. Title the first new column with the heading 'Date_Dummy', the second new column with the heading 'Month', the third with 'Day', and the fourth with 'Date'.

4. Select the 'Date_Dummy' field and format the cell type. Under the Format pull-down menu on the toolbar, go to 'Cells'. Within the 'Format Cells' prompt, under the 'Number' tab, select 'Date' from the 'Category' frame. Select the first option, '3/14/2001' and press the OK button.

5. Select cell E2 and write the following formula: $=\$ \mathbf{C 2}$ and press enter. This should return a value in $\mathrm{mm} / \mathrm{dd} /$ yyyy format. Evaluate the month and day of this date (do not worry about the year being "1900" right now).

- IF the date returned in cell E2 is before February $28^{\text {th }}$, continue to step 6.

- IF the date returned in cell E2 is after February $28^{\text {th }}$ of a leap year (look at the respective value under the field 'Year'), continue to step 6.

- IF the date returned in E2 is after February $28^{\text {th }}$ of a perpetual year (a non-leap year), rewrite the formula in cell E2 as the following: $=(\mathbf{\$ C 2}+\mathbf{1})$, and then continue to step 6 .

6. Copy the formula of cell E2 to the clipboard and paste it to each successive cell under the 'Dummy_date' field until either the end of the year is reached or February $28^{\text {th }}$ is reached (Julian date \# 365 or Julian date \# 59, respectively).

7. Look at the next available cell under the 'Dummy_date' field and repeat steps 5 and 6 until every record has a 'dummy date' in $\mathrm{mm} / \mathrm{dd} / \mathrm{yyyy}$ format. Each time you need to write a new formula, be sure to substitute the current record number for the number " 2 " in the formula “=\$C2".

8. Select cell F2 (under the 'Month' field) and write the following formula: =MONTH(E2). Copy this cell and paste it to the remaining cells of the field.

9. Select cell G2 (under the 'Day' field) and write the following formula: =DAY(E2). Copy this cell and paste it to the remaining cells of the field.

10. Select cell H2 (under the 'Date' field) and write the following formula: $=$ DATE(B2,F2,G2). Copy this cell and paste it into the remaining cells of the field.

11. Select and copy all values in the fields 'Dummy_date', 'Month', 'Day', and 'Date' to the clipboard. In Excel 2003, with the selection still highlighted, execute a 'Paste Special' in place. To do this, click under the Edit pull-down menu on the toolbar, and find 'Paste Special'. On the 
'Paste Special' prompt, choose the 'Paste' option 'Values' and press OK. In Excel 2007, with the selection still highlighted, go to the Clipboard section of the Home tab, click on the downward arrow on the 'Paste' button and choose 'Paste Values'. You should notice that the content of each cell is no longer the formula you wrote. The contents should now be the product of those formulas.

Finally, the data are saved (Excel save command) as SitenameMMYY_MMYY'. The data are now cleaned and ready for analysis. The file name includes the following:

a) Sitename $=$ Name of the weather station (for example, Mathews Arm = MatArm)

b) $\mathrm{MM}=$ Month that the data begin

c) $Y Y=$ Year that the data begin

d) $\mathrm{MM}^{\prime}=$ Month that the data end

e) $\mathrm{YY}^{\prime}=$ Year that the data end

Please note: At this point, each worksheet contains categorical data associated with all weather variables, but only data fields related to the primary variable for the worksheet are clean. For example, air data are visible within the worksheet for soil data. However, only the fields related to soil data have been cleaned. In this case, all fields related to air data may be erroneous and should not be used for any purpose. Cleaned air data can be found in the air data worksheet. During the process described in the Data Analysis processing stream, only valid data are moved to a new worksheet for further analysis.

\section{Time Series Inconsistencies in the Weather Station Data}

It is extremely difficult to keep all weather stations operating at all times in the SNP. They are subjected to harsh conditions in an uncontrolled environment where many incidents may occur, including interferences from wildlife and humans. Because of these conditions, not all instruments on a weather station may be functioning properly at any given time. For this reason, we split the data into three separate variable-type categories to retain logged data for instruments known to be functioning properly and discard data for instruments that are not. Damage to the sensors and data loggers interrupts the continuity of the data stream and results in different temporal extents among the stations (fig. 3).

These 'gaps' in data records are not omissions but are an indication of corrupt and invalid data that have been eliminated in the Data Cleaning Process. 


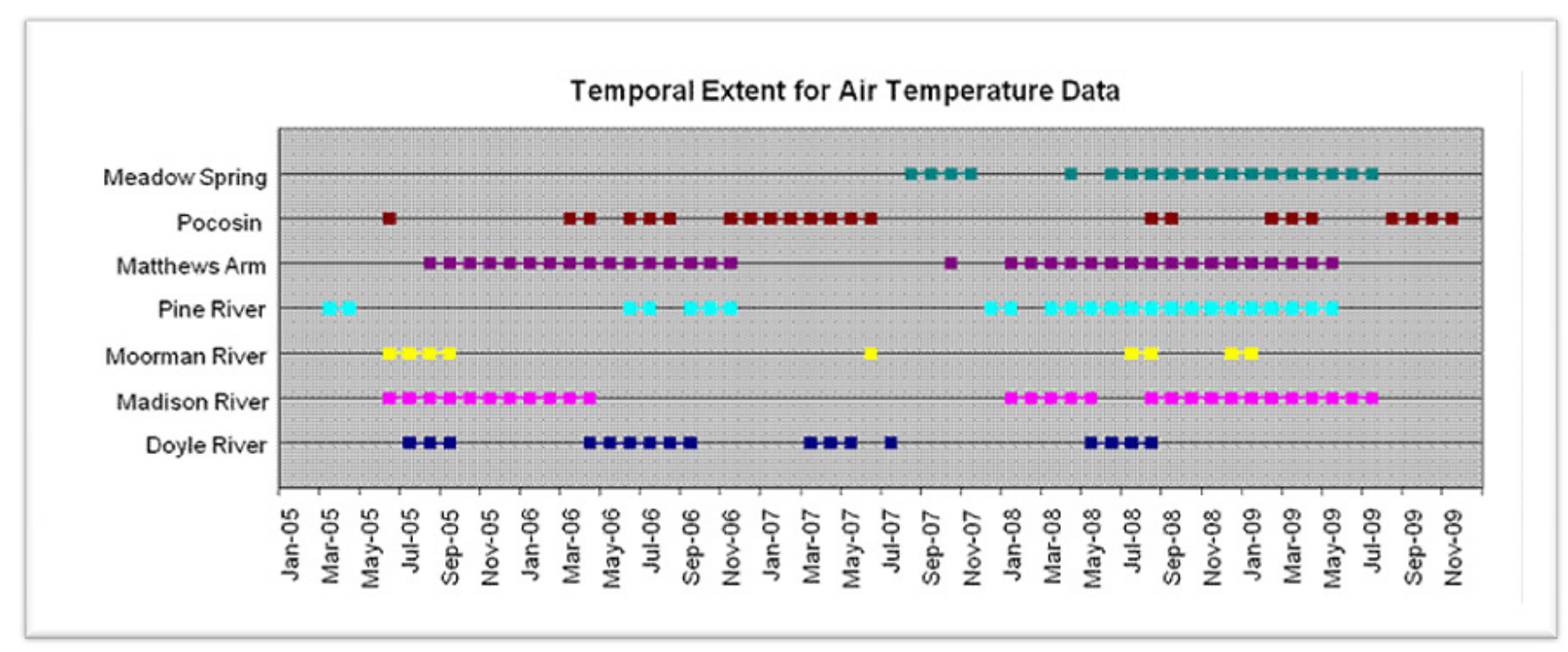

Figure 3. Chart depicting temporal extent of existing air temperature data per weather station between January 2005 and July 2009, Shenandoah National Park.

\section{Data Analysis Processing Stream}

Once the data are cleaned, they are then summarized in Excel using Microsoft Visual Basic ${ }^{\circledR}$ code (described in appendix 2) that produce daily and monthly average maximums, max-maximums, average minimums, and min-minimums. The data can then be plotted with these results (fig. 4). Please note: macros are executed for each data type and each weather station individually.

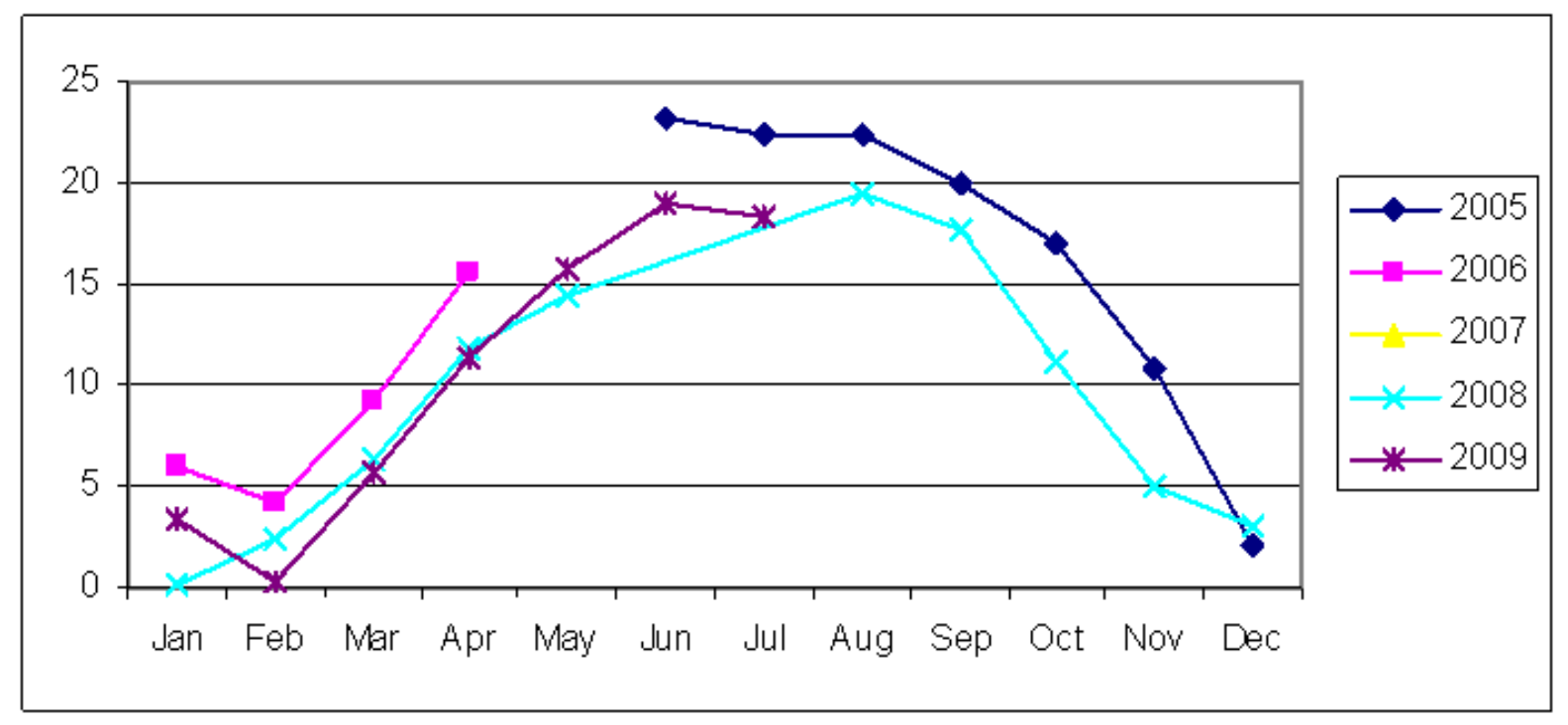

Figure 4. Average monthly maximum air temperature $\left({ }^{\circ} \mathrm{C}\right)$ from the Madison River station, Shenandoah National Park. 
The following steps describe how to utilize these macros in an Excel workbook:

1. Create an Excel workbook with the following three worksheets: Alldata (as one word), monthly, and daily.

2. Under the Tools pull-down menu (the View tab in Excel 2007) go to Macro, then click 'Macros...' to open the Macro Tool.

3. Name the Macro grabber, then click Create.

4. In Visual Basic, copy and paste the grabber and mo_grabber code from appendix 2 of this document into the module (code) between the text Sub grabber() and End Sub.

5. The only section of the code that needs editing is the 'max_columna' and 'min_columna' values. This code retrieves the maximum and minimum weather data values from the columns they are in. These columns will be different depending on whether you are working with cleaned air temperature data, soil temperature data, or RH data, as well as depending on which station is being viewed. In order to know what values the 'max_columna' and 'min_columna' need to equal within the code, count the number of columns from the Date $(\mathrm{H})$ column to the maximum and minimum weather data for the grabber macro, and from the Month (F) column for the mo_grabber macro (fig. 5).

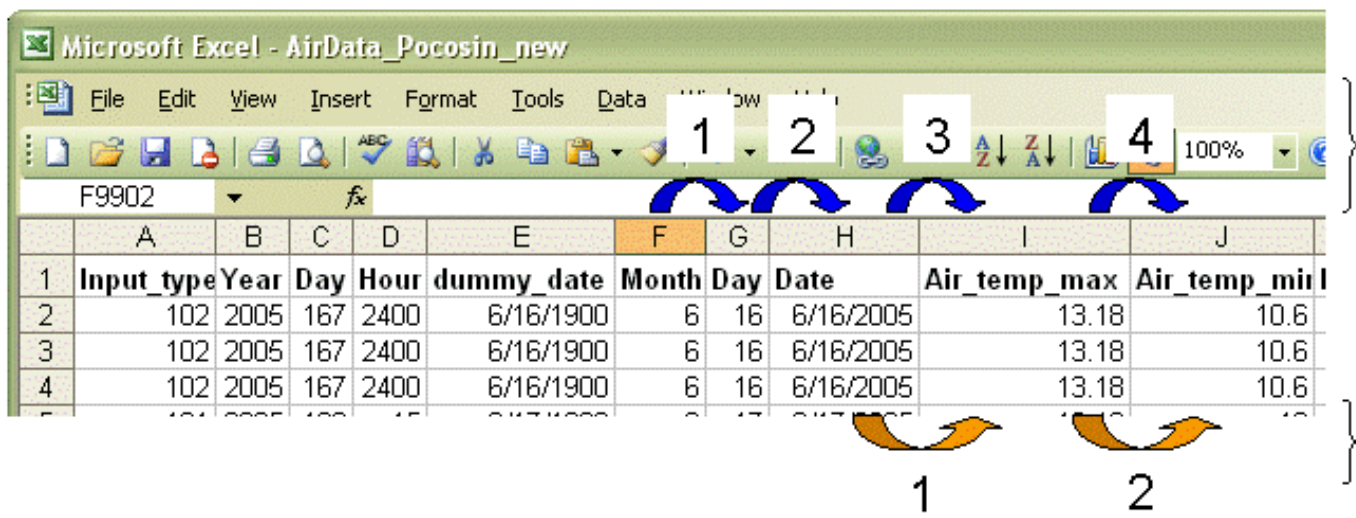

Monthly column values would be ' 3 ' and ' 4 ', for 'max_columna' and 'min_columna', respectively in the mo_grabber macro.

Daily column values would be ' 1 ' and ' 2 ' in the grabber macro.

Figure 5. Example showing how to assess what values should be given to the 'max_columna' and 'min_columna' code within the grabber and mo_grabber macros. Pocosin air data are shown. Please note: Values will be different for the other data types (for example, soil temp or $\mathrm{RH}$ ), as well as for different weather stations.

6. With cleaned data for one data type that is being summarized in the Alldata worksheet, the macro can be run. After the grabber macro has run successfully the worksheet labeled 'daily' should be populated with daily averages of the weather data. The headers for the 'daily' data are as follows: Date (B2), max (C2), average max (D2), min (E2), average min (F2), n (G2), last $\max (\mathrm{H} 2)$, last min (I2).

7. In order to create the monthly averages, repeat the previous steps with the mo_grabber macro. For this code, the edits to 'max_columna' and 'min_columna' need to be counted from the month column (F) in the Alldata worksheet. Once the mo_grabber macro is run, the headers for the new 'monthly' data are as follows: month (B2), year (C2), max (D2), average max (E2), min (F2), average $\min (\mathrm{G} 2), \mathrm{n}(\mathrm{H} 2)$.

These data can then be plotted and analyzed (fig. 5). 


\section{Adding New Weather Station Data to Existing Data}

As new data files are collected from the weather stations, they are cleaned and integrated into the data analysis process. The following steps are taken with new .dat files:

1. Open a new Excel workbook and name the first worksheet RawData and add the headers (table 1) for the station.

2. Import new dat files by following the steps in the Data Processing section of this document.

3. Once the dat files are loaded, and given cell colors if there is more than one file, follow the steps to identify and delete duplicate records.

4. Copy the RawData worksheet three times for the three data types (soil temperature, air temperature, and $\mathrm{RH}$ ) using the worksheet naming conventions: Regorg[sitename]_[variable type] (for example, ReorgPocosin_Soil).

5. Within the new worksheets with the copied RawData, follow the steps to manually delete obviously inaccurate readings within the data in the Data Processing section of this document.

6. Next, follow the steps to create a date field in the $\mathrm{mm} / \mathrm{dd} / \mathrm{yyyy}$ format from the Julian date serial number.

7. Save the Excel workbook as SitenameMMYY_MMYY (begin and end dates of the data).

8. Once the data are cleaned, they can be copied into their respective Data Analysis workbooks in the Alldata worksheet following the previous data; now the new data have been combined with the previous data. This should be done for all data types: air temp, soil temp, and RH.

9. Re-run macros (grabber and mo_grabber) to create daily and monthly summary tables that include the new data in the daily and monthly worksheets for all data types.

\section{File Naming Conventions}

It is important to maintain a consistent file structure. If the weather station data are being processed and analyzed for the Shenandoah National Park Phenology Project, certain file naming conventions need to be applied (table 2).

Table 2. File naming conventions.

\begin{tabular}{lcl}
\hline \multicolumn{1}{c}{ File type } & \multicolumn{1}{c}{ File name } & \multicolumn{1}{c}{ Example } \\
\hline $\begin{array}{l}\text { MS Excel workbook } \\
\text { for cleaning process }\end{array}$ & SitenameMMYY_MMYY & Pocosin0809_0410.xls \\
$\begin{array}{l}\text { MS Excel workbook } \\
\text { macros are run in }\end{array}$ & [Sitename]_[DataType]Data & Pocosin_AirData.xls \\
DAT files & $\begin{array}{l}\text { SitenameYYYYMM- } \\
\text { YYYYMM }\end{array}$ & Pocosin200506_20012.dat \\
\hline
\end{tabular}




\section{Conclusion}

This report describes the process that the U.S. Geological Survey uses to quality assess and quality control data downloaded from project weather stations in the SNP. The weather data described in this document are provisional pending further analysis and peer review. However, if these data would assist your research, they have been made available from the USGS Eastern Geographic Science Center (EGSC). To request them, contact:

John W. Jones

Phone: (703) 648-5543

Fax: (703) 648-4603

Email:jwjones@usgs.gov

\section{Acknowledgments}

The authors would like to extend their thanks to Cindy Cunningham for all of her hard work and dedication with the operation of the weather stations. We would also like to thank Allisyn HudsonDunn, Natlee Hernandez-Guevara, and Louis Keddell for thoroughly testing the manual's procedures.

\section{Bibliography}

Jones, J.W. and Osborne, J.D., 2008, Detecting evidence of climate change in the forests of the Eastern United States: U.S. Geological Survey Fact Sheet 2008-3046, 2 p. 


\section{Appendix 1. Detailed flowchart of data processing steps.}

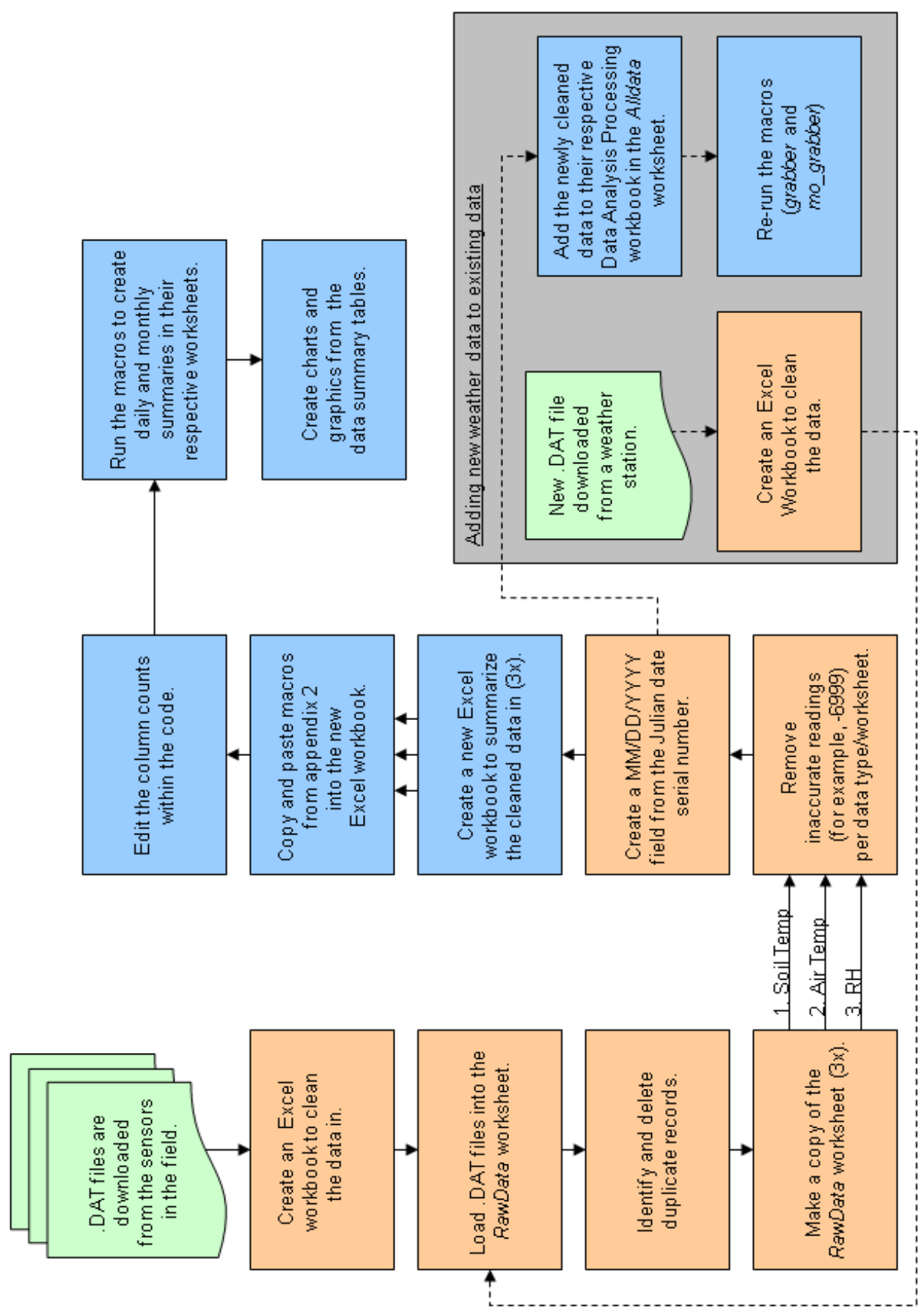




\title{
Appendix 2. Macros used in processing data for the Shenandoah National Park Phenology Project.
}

\author{
' grabber Macro
}

1

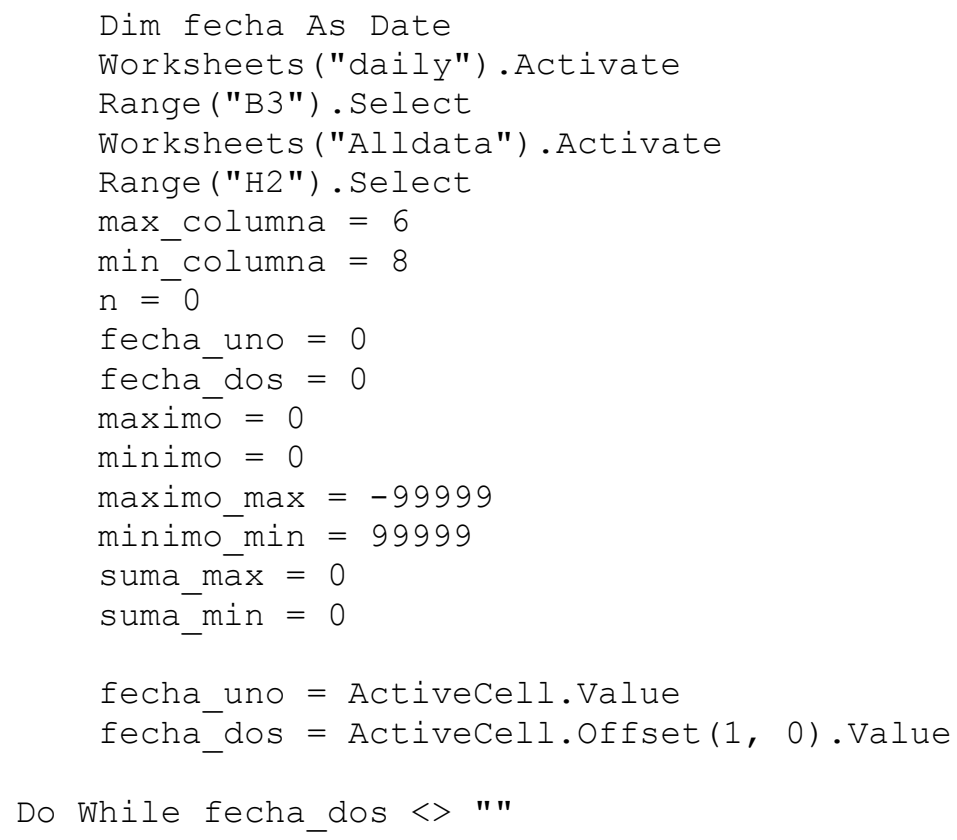

\section{' begining of grab day}

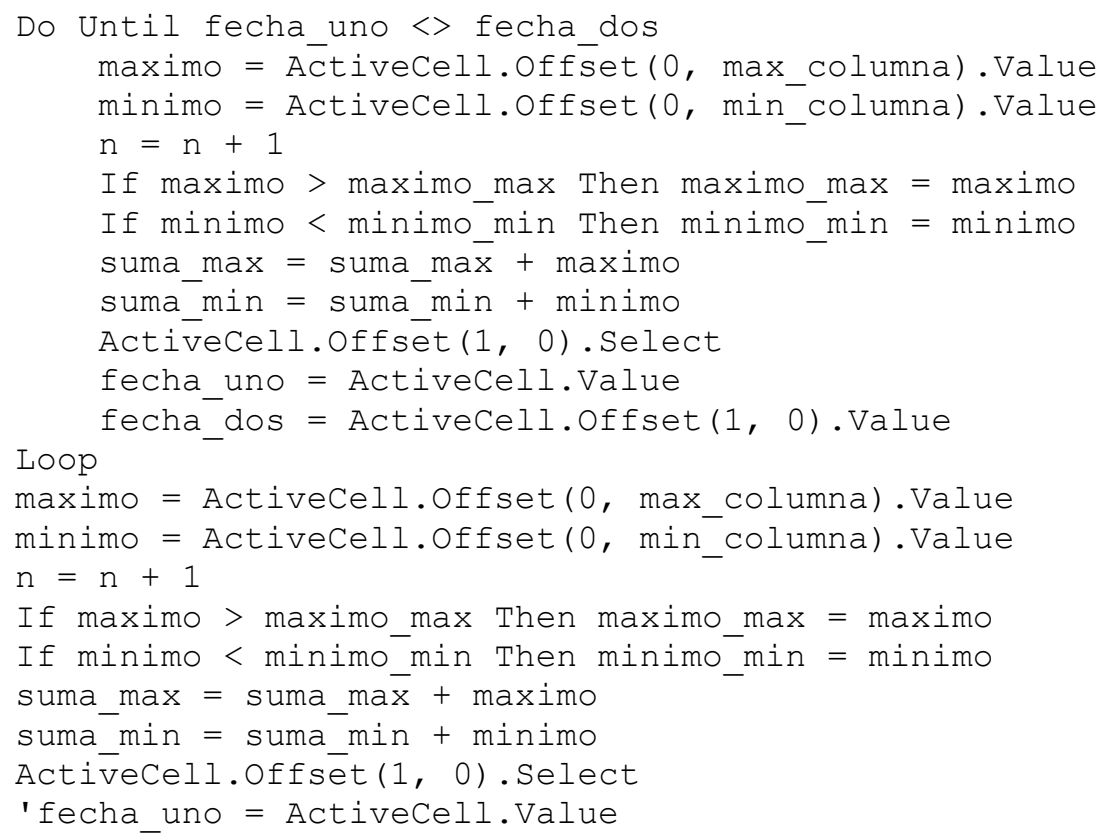




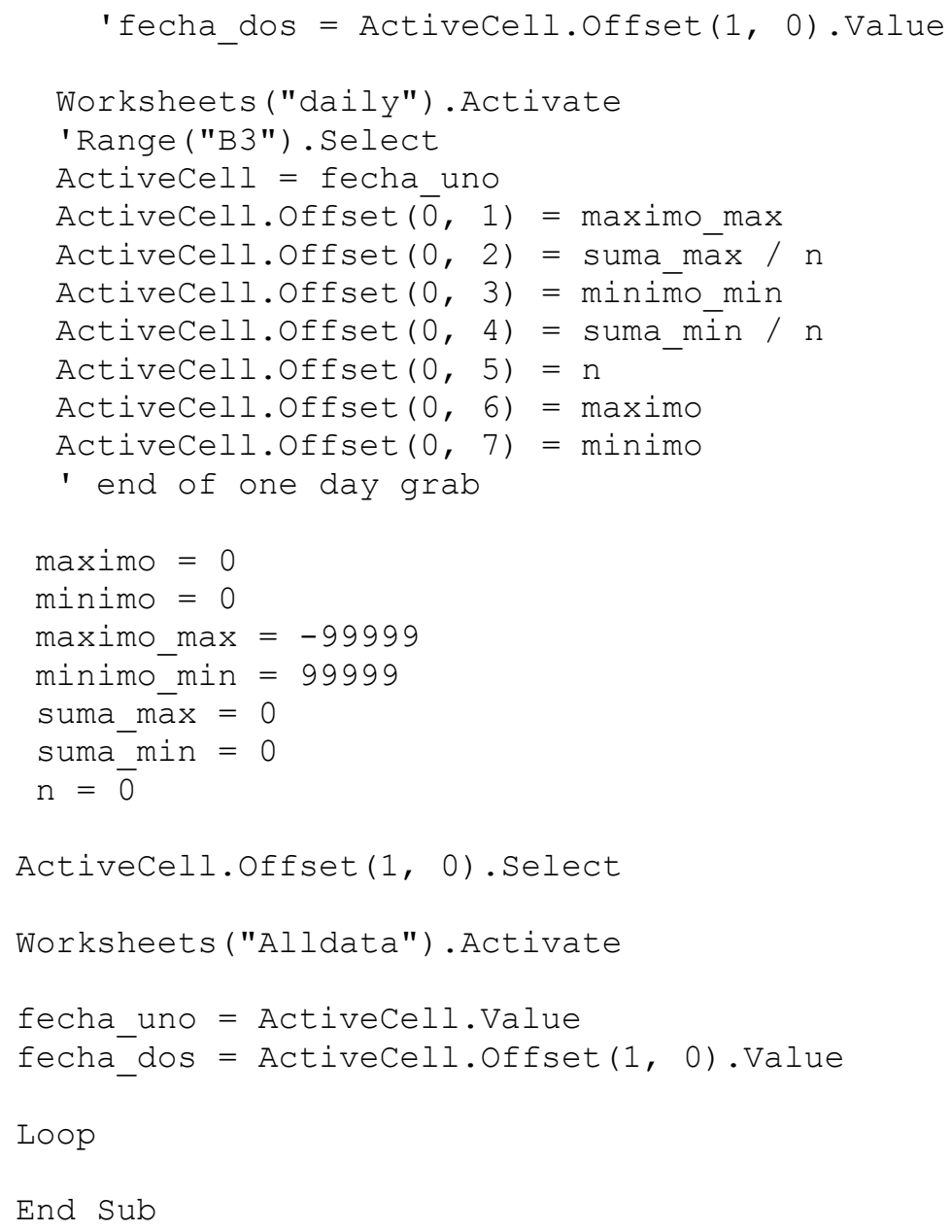

\section{Sub mo_grabber()}

,

' monthly grabber Macro

I

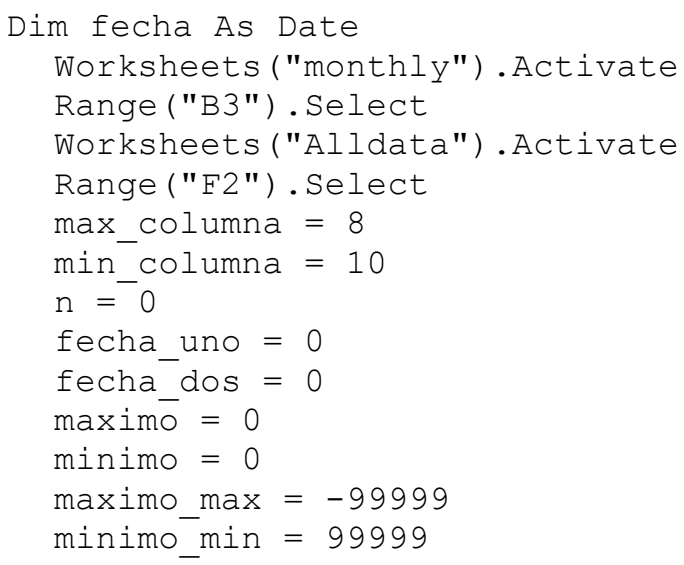


fecha uno = ActiveCell.Value

fecha_dos = ActiveCell.Offset $(1,0)$.Value

Loop 